\title{
Sorption characteristics studies of eco-friendly polymer composites
}

\author{
Vladimir Lebedev ${ }^{1, *}$, Tetiana Tykhomyrova ${ }^{1}$, Oleksandr Lytvynenko $^{2}$, Alla Grekova ${ }^{3}$, and Svitlana Avina ${ }^{1}$ \\ ${ }^{1}$ National Technical University «Kharkiv Polytechnic Institute», 61002 Kyrpychova str., 2, Kharkiv, Ukraine \\ ${ }^{2}$ National University, 92037 Torrey Pines Rd 11255 N, La Jolla, California, United States \\ ${ }^{3}$ Odessa National Medical University, 65082 Valikhovsky Lane 2, Odessa, Ukraine
}

\begin{abstract}
This paper presents the results of new composite materials based on polylactide and coffee grounds sorption characteristics study. New material, that include coffee grounds as additive material is cheaper than one of common polylactide. All types of dishes cam be made from new material and they also will be biodegradable, as made from polylactide. The sorption properties and characteristics were tested in different liquid medium. The last was chosen among the most wide spread mediums which are contact with dishes during its operational life. It was found, that optimal content of coffee grounds is $40 \mathrm{wt} \%$ as for level of impact strength also for complex of sorption characteristics.
\end{abstract}

\section{Introduction}

The modern paradigm of global economy and industry is directly related to the concept of "Zero Waste", based on minimum waste generation principle at each stage of material or product production, operation and disposal $[1,2]$. That is why today we are talking about the widespread use of so-called "eco-" or "biomaterials" that do not harm the environment. This trend can be found both in various branches of modern industry and in ordinary household spheres of human life: food, hygiene, entertainment industry and others. We faced with wastes every minute in our life. Even common phenomenon such as making coffee at home or in a restaurant leads to the generation of waste's large amounts, that usually called coffee grounds.

Coffee consumption in Ukraine is more than 15,000 tons per year and continues to grow on average by $5 \%$ per year [10]. Today, coffee is a popular raw material for making broad range of beverages, as well as the provision of various additional services in hotel and restaurant industry. Its fruits contain a large number of substances that one of various chemical nature: proteins, carbohydrates, organic acids, fats, alkaloids, in particular caffeine.

High demand for this species marketable products, leads to the emergence of new production plants in our country instant coffee. And like any industry, coffee production cannot be waste-free. The main waste of this class of enterprises is coffee grounds or coffee cake. Coffee grounds is a product obtained from the industrial production of instant coffee or waste remaining after the preparation of a beverage from ground coffee. Coffee grounds is a valuable organic raw material and contains a large number of nutrients, primarily proteins. In the production of one ton of dry instant coffee, the yield of absolutely dry cake is 1.5 tons. Wet thicket molds quickly, so storage is required its additional drying. According to the generally accepted classification of waste, it is household organic waste [3]. In terms of the Zero Waste concept, most developed countries in the last 20 years have begun to actively use coffee grounds as a valuable resource that corresponds to the concept of sustainable development.

World trends analyze allowed to outline the main directions of coffee grounds:

- utilization in agriculture in the form of additives in fertilizers or soils. however, this direction of dry coffee grounds use is rather limited because it is not studied transformation of useful substances from a field to soil. That is why, you can find a lot of amateur information about the use of coffee grounds in some farms, but thorough research has not yet been conducted. You can also find information about the general harm of coffee grounds due to its acidic pH level, at the same time, it is generally studied to use wet coffee grounds as a basis for growing mushrooms, in particular champignons and coffee grounds using as fuel;

- use as an abrasive material in the manufacture of cosmetics, including creams, scrubs, soaps, etc. Manufacturers of so-called "green" or "eco" cosmetics prefer to use coffee grounds. However, this direction is able to dispose a limited amount of coffee grounds waste;

- use of coffee grounds in modern art, including for the production of jewelry, painting and various installations;

- use as an additive to polymeric materials to reduce the cost of the final product. The most forward-looking conception is to produce biodegradable polymer dishes,

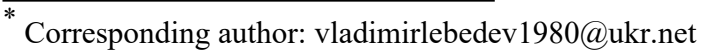


which is dominated by an organic additive - coffee grounds.

The last conception allows to utilizate a large volumes of coffee grounds the same time to achieve the principle of "Zero Waste" when using bioplastics. The concept of sustainable development implies the recycling of materials that were previously considered waste. The criterion for the expediency of using waste as a resource can be not only the economic component, but also a decrease environmental impact. At the same time, the life cycle of a new material object should not increase the environmental impact. Coffee grounds, getting to landfills for solid household waste, within three days become a breeding ground for mold, which quickly spreads to other elements of the landfill.

Using of coffee grounds waste as a filler, you can get a product that haven't negative environmental impact with low price. That is why the development of biodegradable polymer composite materials based on bioplastic such as polylactide (PLA) and coffee grounds waste is very relevant.

\section{Literature data analysis and problem statement}

Today, there is a significant number of scientific studies of coffee grounds as a filler in polymer composite materials $[4,5,6,7]$. At the same time, research in the field of using coffee grounds as filler for new biodegradable composite materials is rarely found $[8,9]$. The objective of this research was to determine the effect of spent coffee grounds filler on the physical and mechanical properties of PLA bio-composite film. The bio-composite film was fabricated by a twin-screw and blow film extruder.

In researc [9] characterizes and compares coffee chaff and spent coffee grounds, the two most useful coffee waste products, and evaluates their performance as fillers and/or reinforcing agents in polymer composites.

We have previously studied [10] chemical, physical, mechanical and operational properties of new high-filler composite based on PLA. As shown, the highest performance indicators were characterized for compositions with a content of coffee grounds filler from $40 \%$ to $60 \%$ wt. It is also noticed, that using coffee grounds as fillers for polymer materials can decrease the total volume of it at landfills faster than any other method of coffee ground reuse. Further research the level of sorption stability for developed materials to the most characteristic environments of their operation is perspective.

\section{Study purpose}

The aim of the research was study sorption resistance of biodegradable polymer composite materials based on PLA and coffee grounds waste.

To achieve this aim in the work it was necessary to perform the following tasks:
- to study the effects of coffee grounds waste on the mechanical characteristics of biodegradable polymer composite materials based on PLA;

- to research the sorption characteristics of the developed materials to the most characteristic environments of their operation.

\section{Materials and methods}

The objects of study were:

- extrusion PLA of the Terramac TP-4000 brand;

- coffee grounds waste, gathered in 8 different coffee shops in Kharkiv and dried to moisture content $50 \%$ Coffee grounds waste have a polyfractional composition in the particle size limit from 0.5 to $1 \mathrm{~mm}$. Using IR spectroscopy methods, it has been shown [10] that coffee grounds, in their chemical composition, are characterized by up to $6 \%$ or more content of caffeine, alkaloids and their companions, up to $1 \%$ of chlorogenic acids and their derivatives content.

Composites were obtained by extruding pre-prepared raw materials in a single-screw laboratory extruder at a temperature of $170-200^{\circ} \mathrm{C}$ and a roll rotation speed of $30-100 \mathrm{rpm}$. The $\mathrm{L} / \mathrm{D}$ ratio of the extruder is 25 , and in order to increase the uniformity of dispersed waste distribution in the finish compositions, 2 mass passes were used to obtain finished samples. It was made 20 parallel experiments for each composition, statistical processing was made by characteristics such as arithmetic mean, standard deviation and variation coefficient.

The study of impact strength and breaking stress during bending of the samples without notching at a temperature of $20^{\circ} \mathrm{C}$ was carried out on a pendulum head according to ISO 180 and ISO 178, respectively.

Microscopic studies were carried out using the electron microscope Digital Microscope HDcolor CMOS Sensor (China).

The chemical method for determining the porosity of the paint coating is to identify violations of its continuity in the formation of points of the turnbule salt in the reaction of the reagent - red blood salt $\mathrm{K}_{3}\left[\mathrm{Fe}(\mathrm{CN})_{6}\right]$ with $\mathrm{Fe}^{2+}(\mathrm{pH} \leq 7)$, which occur due to corrosion of steel and diffuse to the surface of the coating. To assess the destruction of the coating from the formation of bubbles, coating samples applied to a steel substrate measuring $10 \times 15 \mathrm{~cm}$ and sealed at the edges are placed in the operating environment for 7 days at a temperature of $20^{\circ} \mathrm{C}$.

The method of evaluation is to determine the surface area of the coating, which is destroyed by bubbles and the linear size of the bubbles (diameter and depth of the lesion). The degree of destruction of the coating due to the formation of bubbles is assessed on a five-point scale.

Sorption characteristic of the samples was determined as the amount of reagents absorbed by the sample (size $15 \times 10 \times 1.5-4.5 \mathrm{~mm})$ as a result of its stay in the model liquid (water, drink Coca-Cola, 5\% surfactant ) for 30 days at room temperature (about $18-20^{\circ} \mathrm{C}$ ). 


\section{Results}

The first step was to investigate the physical and mechanical properties of the obtained biopolymer composite material: impact strength and breaking stress during bending (figure 1). It is well known, filled polymeric materials must have a higher impact strength than homopolymers. Our new materials has shown the same properties - the impact strength for coffee-filled composite (40 wt.\% coffee grounds on $60 \mathrm{wt} . \%$ PLA) is 2.5 times more than for the sample without coffee grounds. the value of impact strength has tendency to increasing with increasing volume of coffee grounds.

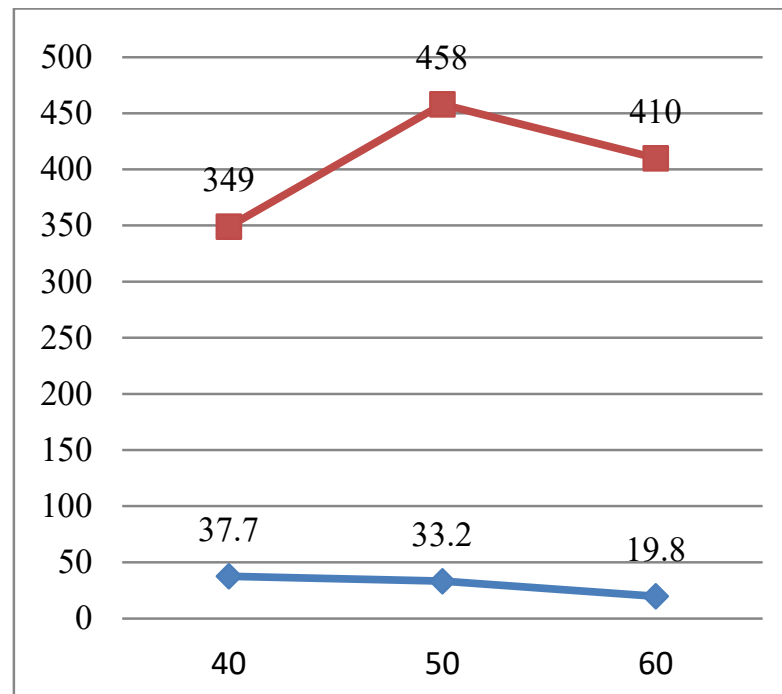

Coffee grounds filler content, $\%$ wt

-Impact strength, $\mathrm{J} / \mathrm{m} 2$

Breaking stress during bending, $\mathrm{MPa}$

Fig. 1. Physical and mechanical properties of designed composite material based on PLA.

Level of impact strength influence the possibility for forming various products of composite material. As we see, for new composite material impact strength is within the required value [10].

The next step was sorption properties study of new composite material. Note that the samples with the lowest porosity were selected using a microscope, because in the laboratory a significant part of the samples have an uneven surface with large pores and cavities, which will distort the data on water (and any other liquid) absorption [11].

At the first stage of the sorption characteristics study for new composite material, its porosity was determined and the tendency to form pulp bubbles in two types of operating media - water (non-purified drinking water) and $5 \%$ surfactant solution (surfactant) was evaluated. It is in these types of media PLA-based dishes with coffee grounds will be immersed during operation (washing dishes, pouring into the dishes of coffee or other beverages) [11].
Table 1 shows the results of the study of compositions based on PLA with different content of coffee grounds on the porosity and tendency to making bubble. Data analysis of table 1 allows to choose as optimal for further operation a composition with a content of coffee grounds $40 \mathrm{wt} \%$, because it demonstrate the same properties as its original polymer without adding the condensate [11]. The increase in the content of coffee grounds leads to its uneven distribution in the surface layer of the composition and high porosity of the samples.

Table 1. Porosity study of compositions based on PLA with different content of coffee grounds.

\begin{tabular}{|c|c|c|c|c|c|}
\hline \multirow[t]{2}{*}{ № } & \multirow{2}{*}{$\begin{array}{l}\text { Coffee } \\
\text { grounds } \\
\text { contents, } \\
\text { wt. } \%\end{array}$} & \multicolumn{2}{|c|}{$\begin{array}{l}\text { Porosity of the } \\
\text { coating, score, in } \\
\text { the environment }\end{array}$} & \multicolumn{2}{|c|}{$\begin{array}{c}\text { Destruction of the } \\
\text { surface due to the } \\
\text { formation of bubbles, } \\
\text { A, in the liquid } \\
\text { medium }\end{array}$} \\
\hline & & water & $\begin{array}{c}5 \% \\
\text { surfactant } \\
\text { solution }\end{array}$ & water & $\begin{array}{c}5 \% \text { surfactant } \\
\text { solution }\end{array}$ \\
\hline 1 & 40 & 1 & 1 & $\mathrm{~A} 1,00$ & $\mathrm{~A} 1,00$ \\
\hline 2 & 50 & 2 & 2 & $\mathrm{~A} 0,95$ & $\mathrm{~A} 0,93$ \\
\hline 3 & 60 & 3 & 3 & $\mathrm{~A} 0,85$ & $\mathrm{~A} 0,79$ \\
\hline 4 & 0 & 1 & 1 & $\mathrm{~A} 1,00$ & $\mathrm{~A} 1,00$ \\
\hline
\end{tabular}

A necessary and standard characteristic for all polymeric materials, which determines their performance properties, is to determine the diffusion coefficient of the liquid, for which long-term experiments are performed according to the method described in [11]. The samples were immersed in water and periodically measured changes in their mass and geometric shape. The results are shown in table 2.

Table 2. The resistance study results of compositions samples based on PLA with different content of coffee grounds to water at a temperature of $20^{\circ} \mathrm{C}$.

\begin{tabular}{|c|c|c|c|c|c|}
\hline \multirow{2}{*}{ Cycle } & & \multicolumn{4}{|c|}{$\begin{array}{c}\text { The increase in the mass of the } \\
\text { samples by numbers, \% }\end{array}$} \\
\cline { 2 - 6 } & $\begin{array}{c}\text { coffee grounds } \\
\text { contents, wt. } \%\end{array}$ & $\mathbf{4 0}$ & $\mathbf{5 0}$ & $\mathbf{6 0}$ & $\mathbf{0}$ \\
\hline A day later & & & & & \\
-1 & & 1,35 & 2,74 & 3,77 & 0,01 \\
-3 & 1,50 & 2,75 & 3,85 & 0,74 \\
-7 & 1,55 & 2,77 & 3,95 & 0,75 \\
-15 & 1,60 & 2,78 & 4,10 & 0,76 \\
-30 & & 1,65 & 2,79 & 4,20 & 0,77 \\
\hline
\end{tabular}

As can be seen from table 2, the original polymer and composition with a content of 40 wt. \% show a small weight gain, which after two months does not exceed $2 \%$. With increasing content of coffee grounds, the increase in the mass of the samples, their water absorption, reaches $5 \%$. But even such indicators are not critical for the manufacture of dishes. However, the composition containing $40 \mathrm{wt} \% \%$ thick is the most resistant to operating loads [11].

Sorption characteristics study of the compositions to the action of aggressive environments was also performed. An analysis of the market for beverages found in coffee shops alongside natural coffee has clearly identified Coca Cola as the most common. The $\mathrm{pH}$ of this 
drink is 2.5 , so it is an acidic environment. Table 3 shows the results of increasing the mass for composition after immersion in Coca Cola.

Table 3. The resistance study results of compositions samples based on PLA with different content of coffee grounds to Coca Cola at a temperature of $20^{\circ} \mathrm{C}$.

\begin{tabular}{|c|c|c|c|c|c|}
\hline \multirow{2}{*}{ Cycle } & & \multicolumn{4}{|c|}{$\begin{array}{c}\text { The increase in the mass of the } \\
\text { samples by numbers, \% }\end{array}$} \\
\cline { 2 - 6 } & $\begin{array}{c}\text { coffee grounds } \\
\text { contents, wt.\% }\end{array}$ & $\mathbf{4 0}$ & $\mathbf{5 0}$ & $\mathbf{6 0}$ & $\mathbf{0}$ \\
\hline A day later & & 4,0 & 6,8 & 5,2 & 0,22 \\
-1 & & 10,1 & 11,3 & 18,2 & 1,1 \\
-3 & & 15,2 & 20,2 & 24,4 & 1,8 \\
-7 & & 28,9 & 36,5 & 40,1 & 2,3 \\
-15 & & 62,5 & 71,2 & 82,5 & 3,0 \\
-30 & & & & & \\
\hline
\end{tabular}

All samples became very brittle after 30 days, and their surface became porous. The increase in the mass of all samples indicates an easier way for the middle of the samples to penetrate the aggressive medium after three days of exposure [36]. As expected, the original polymer has the lowest weight gain, and among the compositions, such properties are inherent in compositions with a coffee grounds content of $40 \mathrm{wt}$. $\%$.

Sorption characteristics study of the compositions to the action of water and a temperature of $100^{\circ} \mathrm{C}$ was made. Table 4 shows the results of increasing the mass for composition after immersion in the water.

Table 4. Sorption characteristics study results of the compositions to the action of water and a temperature of $100^{\circ} \mathrm{C}$.

\begin{tabular}{|c|c|c|c|c|c|}
\hline \multirow{2}{*}{ Cycle } & & \multicolumn{4}{|c|}{$\begin{array}{c}\text { The increase in the mass of the } \\
\text { samples by numbers, \% }\end{array}$} \\
\cline { 2 - 6 } & $\begin{array}{c}\text { coffee grounds } \\
\text { contents, wt. \% }\end{array}$ & $\mathbf{4 0}$ & $\mathbf{5 0}$ & $\mathbf{6 0}$ & $\mathbf{0}$ \\
\hline A day later & & 5,2 & 7,8 & 10,9 & 0,35 \\
-1 & & 5,9 & 8,5 & 11,8 & 0,38 \\
-3 & & 7,8 & 9,3 & 12,5 & 0,42 \\
-7 & & 15,2 & 24,3 & 30,8 & 0,55 \\
-15 & & 21,2 & 35,6 & 45,6 & 0,68 \\
-40 & & 28,5 & 42,8 & 52,1 & 0,77 \\
\hline
\end{tabular}

The composition, which contains 50 and 60 wt. \% of coffee grounds compared to that containing $40 \mathrm{wt} \%$ during 15 days of immersion in boiling water, shows an increase in weight of almost $2 \%$ more. This is not critical given this figure, but still should prefer a composition with a lower content of thick.

Sorption characteristics study of the compositions to the action of aggressive media in the form of anionic-type surfactants at a concentration of $5 \%$ and a temperature of $75^{\circ} \mathrm{C}$ was made. Table 5 shows the results of increasing the mass for composition after immersion in the surfactant. As you can see from the results of the study, after 7 days the weight gain is slow and does not exceed the average for all samples with coffee grounds - samples with 40,50 and $60 \%$ coffee grounds waste content of $0.09 \%$ per cycle.
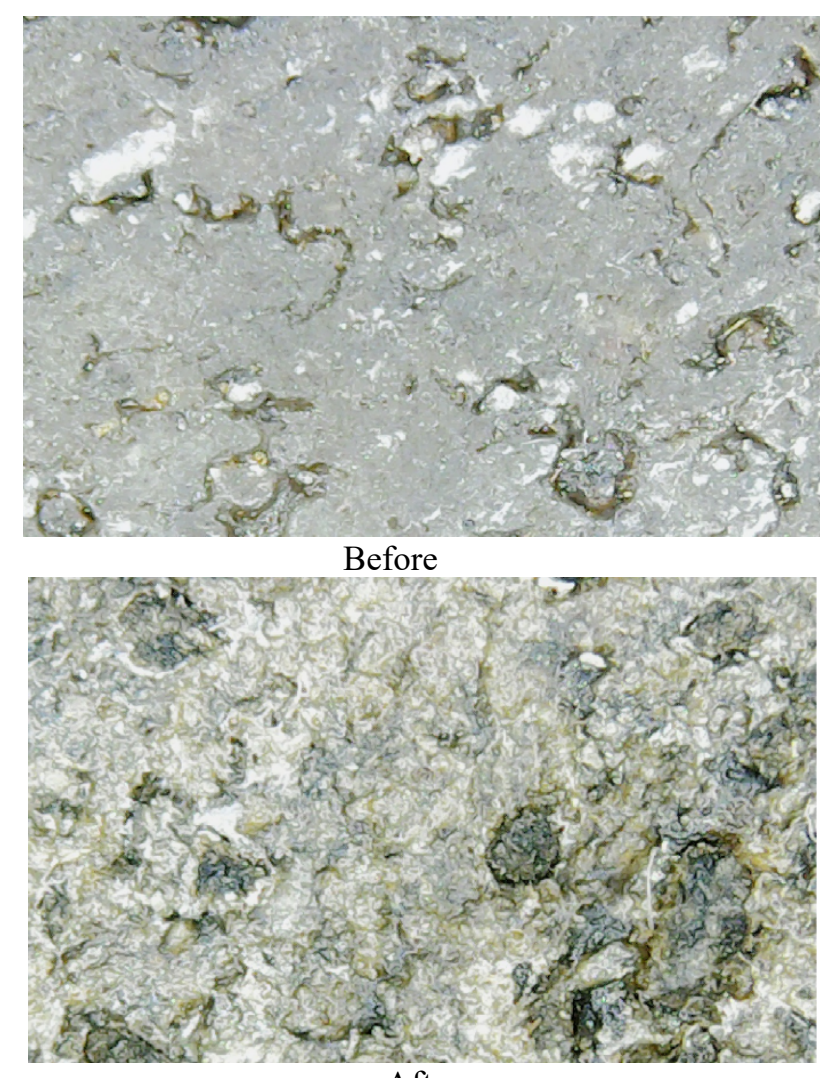

After

A

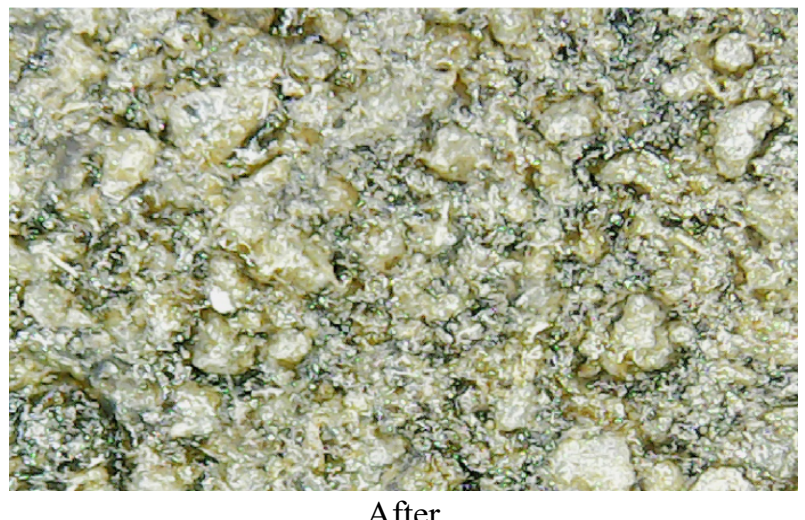

After

$\mathrm{B}$

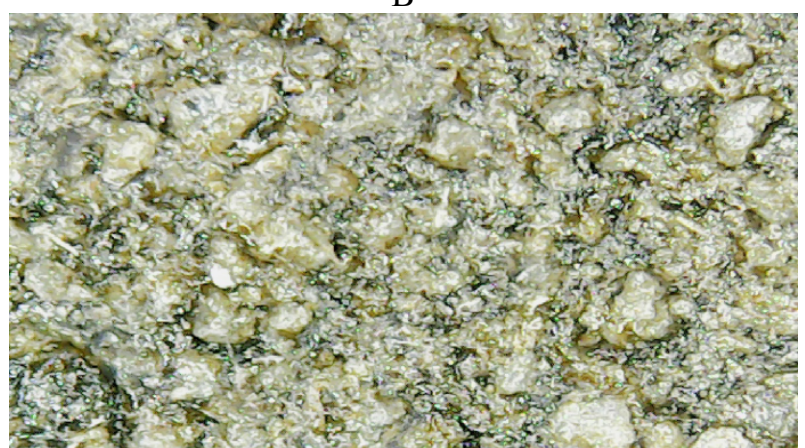

After

C

Fig. 2. Surface's micrographs of new compositions with 40 wt. $\%$ coffee grounds waste content before and after the sorption characteristics study in different model environments: A - water at a temperature of $20^{\circ} \mathrm{C}$; B - surfactant anionic type at a concentration of $5 \%$ and a temperature of $75^{\circ} \mathrm{C}$; C - Coca Cola at a temperature of $20^{\circ} \mathrm{C}$. 


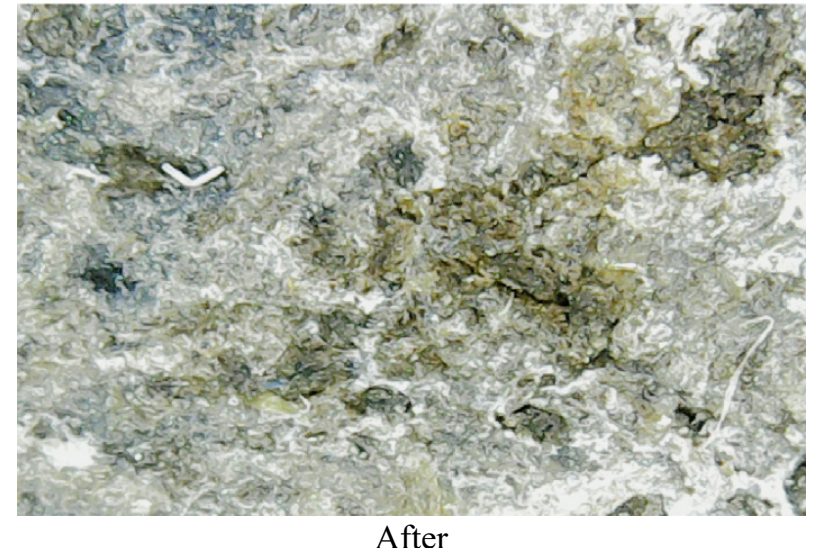

A

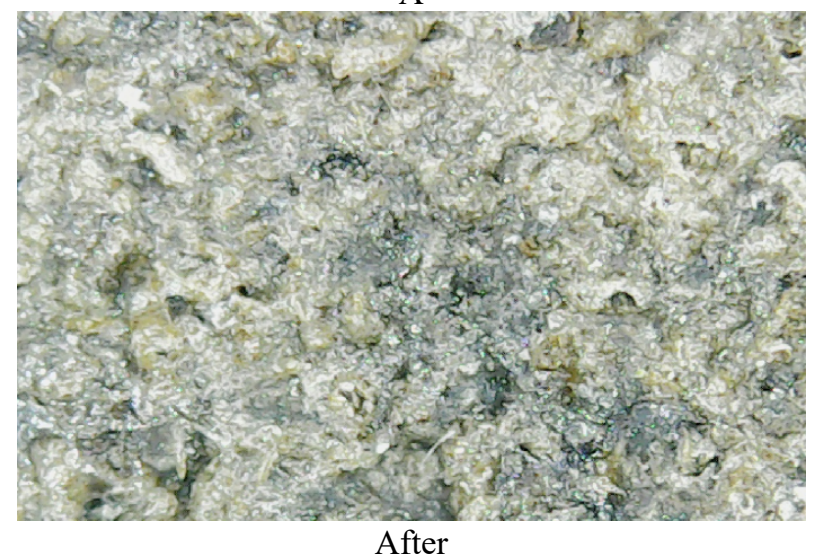

B

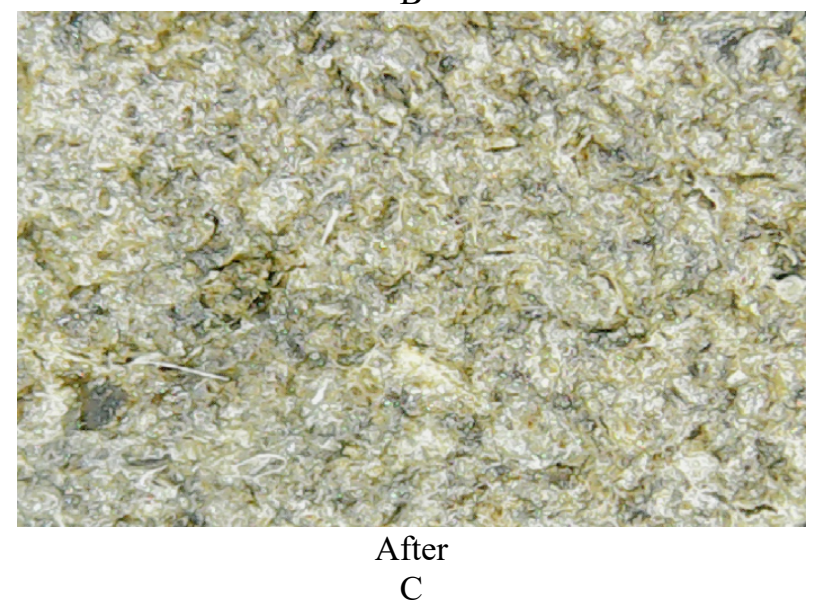

Fig. 3. Surface's micrographs of new compositions with $50 \mathrm{wt}$. $\%$ coffee grounds waste content before and after the sorption characteristics study in different model environments: A - water at a temperature of $20^{\circ} \mathrm{C}$; B - surfactant anionic type at a concentration of $5 \%$ and a temperature of $75^{\circ} \mathrm{C}$; C - Coca Cola at a temperature of $20^{\circ} \mathrm{C}$

Starting from 8 days, the increase in weight can be up to $0.9 \%$ per cycle, constantly increasing to 40 days. For the original PLA polymer, there is also an increase in the rate of weight gain starting from 15 days. This behavior of the compositions and the original PLA is due to the ability to biodegrade products from them under the condition of creating a temperature greater than $65^{\circ} \mathrm{C}$. That is, the results obtained prove, including the actual ability to biodegrade compositions with a thicker based on PLA.

Equilibrium, the end of the water absorption process during the study period was not reached, but the tests are ongoing. The equilibrium state will be characterized by a straight line on the graph or no increase in the mass of the samples. Based on experimental data according to the method described in [11], the diffusion coefficient for the samples was calculated (table 6).

Table 5. Sorption characteristics study results of the compositions to the action of aggressive media (surfactants of the anionic type at a concentration of $5 \%$ ) and a temperature of $75^{\circ} \mathrm{C}$.

\begin{tabular}{|c|c|c|c|c|c|}
\hline \multirow{2}{*}{ Cycle } & & \multicolumn{4}{|c|}{$\begin{array}{c}\text { The increase in the mass of the } \\
\text { samples by numbers, \% }\end{array}$} \\
\cline { 2 - 6 } & $\begin{array}{c}\text { coffee grounds } \\
\text { contents, wt. \% }\end{array}$ & $\mathbf{4 0}$ & $\mathbf{5 0}$ & $\mathbf{6 0}$ & $\mathbf{0}$ \\
\hline A day later & & & & & \\
-1 & & 6,3 & 8,9 & 11,2 & 0,89 \\
-3 & & 7,1 & 10,2 & 13,4 & 0,92 \\
-7 & & 7,9 & 11,1 & 15,1 & 0,99 \\
-15 & & 18,9 & 25,6 & 28,9 & 1,8 \\
-30 & & 24,6 & 34,5 & 39,3 & 2,6 \\
-40 & & 32,6 & 44,5 & 58,2 & 3,9 \\
\hline
\end{tabular}

Table 6. Water diffusion coefficient in samples of compositions based on PLA with different content of coffee grounds.

\begin{tabular}{|c|c|c|c|}
\hline $\begin{array}{c}\text { Samples } \\
\text { number }\end{array}$ & $\begin{array}{c}\text { PLA content, } \\
\text { wt. \% }\end{array}$ & $\begin{array}{c}\text { coffee grounds } \\
\text { contents, wt. \% }\end{array}$ & $\begin{array}{c}\mathbf{D} \cdot \mathbf{1 0 1 0} \\
\mathbf{s m}^{\mathbf{2}} / \mathbf{s}\end{array}$ \\
\hline 1 & 60 & 40 & 0,72145 \\
\hline 2 & 50 & 50 & 0,81526 \\
\hline 3 & 40 & 60 & 0,86998 \\
\hline 4 & 100 & 0 & 0,63085 \\
\hline
\end{tabular}

The data in table 4 indicate the hydrophobic nature of the surface of both the source polymer material PLA and compositions based on them [11].

In fig. 2-4 shows surface's photomicrographs of new compositions before and after the sorption characteristics study in different model environments.

As can be seen from Figure 3-5, the smallest changes in the surface can be observed for compositions with a coffee grounds content of 40 wt. $\%$, which, as shown above, have the best sorption characteristics in different model environments.

\section{Conclusions}

The designed and studied in article polymer composites on the basis of PLA and coffee grounds solve the problems of recycling food industry waste in the form of coffee grounds and expand the possibilities of its rational utilization for agriculture. The use of coffee grounds as a filler for biodegradable polymeric materials can significantly reduce its quantity at landfills and obtain a new material that will be biodegradable. Thus, as a result of the conducted researches the rather high level of sorption resistance of the developed eco-friendly polymer composites on the basis of PLA and coffee grounds is shown. It is founded that the optimal strength characteristics have compositions with a content of coffee grounds waste of $40 \mathrm{wt} . \%$. The study of compositions based on PLA with different content of coffee grounds on the porosity and tendency to making bubble is presented. 
Sorption characteristics study of eco-friendly polymer composites based on PLA and coffee grounds waste are shown for different liquid media: water, surfactants and Coca-Cola. The obtained dates indicate the hydrophobic nature of the surface of both for PLA and compositions based on them. It is shown that the composition with a content of $40 \mathrm{wt} . \%$ is most resistant to operating loads in different model liquid mediums. According to their sorption characteristics, the studied composites can be recommended for the production of reusable tableware and kitchen utensils, food containers and packaging. The study of the developed eco-friendly polymer composites for their main performance indicators in the conditions of field tests looks prospective.
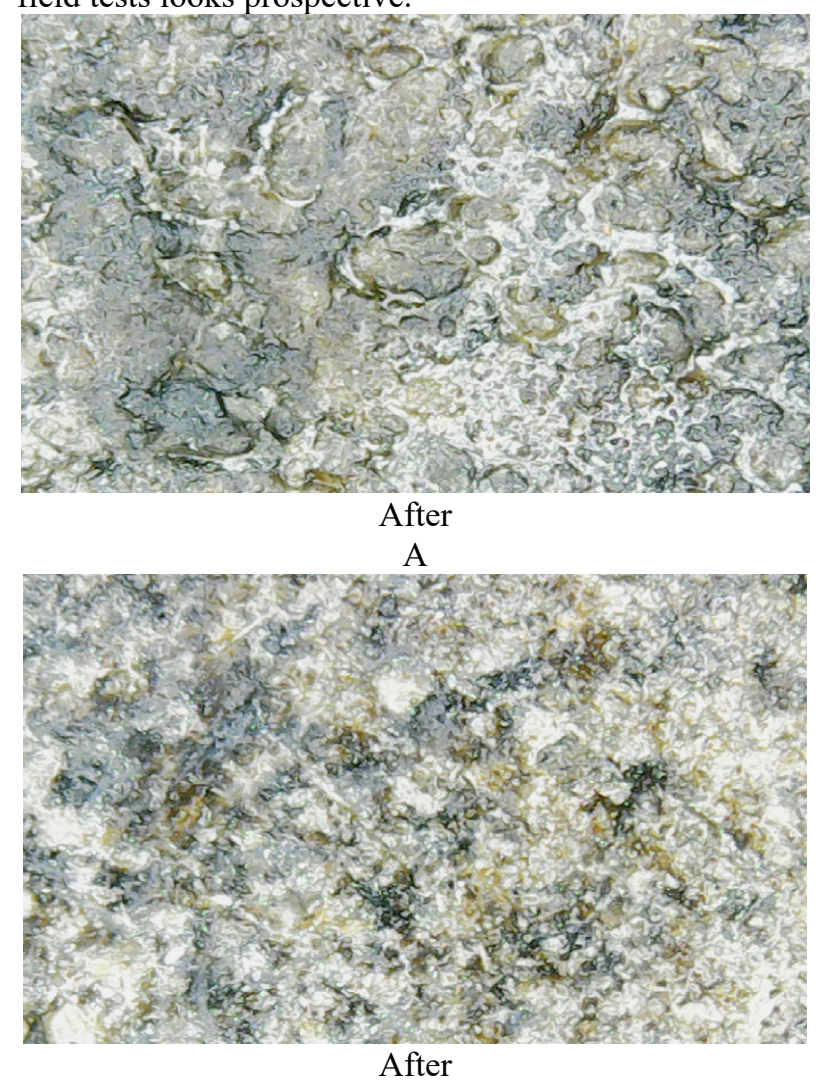

B

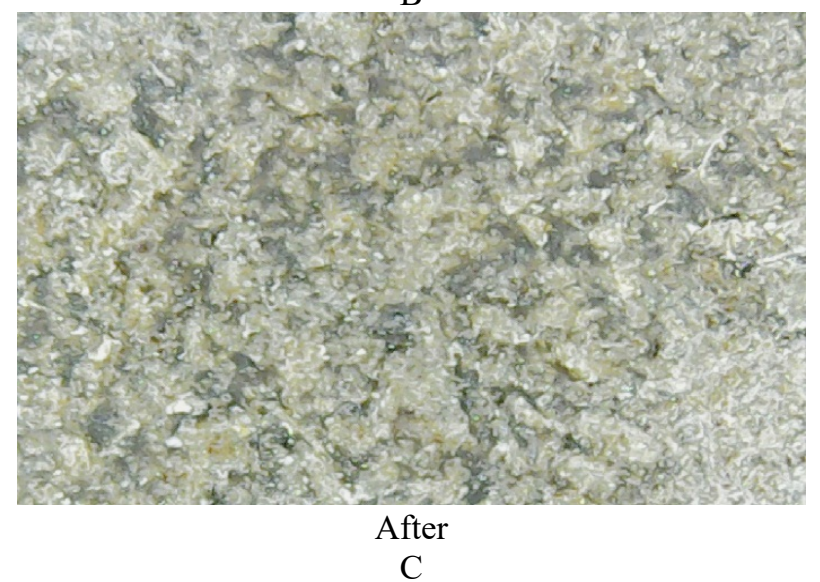

Fig. 4. Surface's micrographs of new compositions with $60 \mathrm{wt}$. $\%$ coffee grounds waste content before and after the sorption characteristics study in different model environments: A - water at a temperature of $20^{\circ} \mathrm{C}$; B - surfactant anionic type at a concentration of $5 \%$ and a temperature of $75^{\circ} \mathrm{C}$; C - Coca Cola at a temperature of $20^{\circ} \mathrm{C}$

\section{References}

1. W.R. Stahel, The circular economy, Nature. 531, 435-438 (2016)

2. G. Kaur, K. Uisan, K. Lun Ong, C. Ki Lin, Curr. Opin. Green Sustain. Chem. 9, 30-39 (2018)

3. R. Campos-Vega, G. Loarca-Piña, H.A. VergaraCastañeda, B.D. Oomah, Trends Food Sci. Technol. 45, 24-36 (2015)

4. D. L. Ortiz-Barajas, J. A. Arévalo-Prada, O. Fenollar, Y. J. Rueda-Ordóñez, S. Torres-Giner, Appl. Sci. 10, 6468 (2020)

5. F. Sarasini; J. Tirillò; A. Zuorro; G. Maffei; R. Lavecchia, D. Puglia, F. Dominici, F. Luzi,; T. Valente; L. Torre, Ind. Crops Prod. 118, 311-320 (2018)

6. C. Cecchini, M. Petroni, Plastic Days Materials \& Design. 2, 36-61 (2015)

7. C. Siriwong, S. Boopasiri, V. Jantarapibun, B. Kongsook, S. Pattanawanidchai, P. Sae-Oui, J. Appl. Polym. Sci. 135, 46-60 (2018)

8. N. Suaduang, S. Ross, G.M. Ross, S. Pratumshat, S. Mahasaranon, Materials Today: Proceedings. 17, 2104-2110 (2019).

9. N. Zarrinbakhsh, T. Wang, A. Rodriguez-Uribe, M. Misra, A.K. Mohanty, BioResources. 11, 7637-7653 (2016).

10. V. Lebedev, T. Tykhomyrova, I. Litvinenko, S. Avina, Z. Saimbetova, Materials Science Forum. 1006, 259-266 (2020)

11. M.I. Karyakin, Khimiya. 272 (1988) 